\title{
Antigen-specific tolerization approaches in multiple sclerosis
}

\author{
Lutterotti, A ; Martin, R
}

\begin{abstract}
Introduction: Inhibition of self-reactive T cells through induction of antigen-specific immune tolerance holds the promise of effective treatment of autoimmune pathology with few side effects and preservation of normal immune functions. In multiple sclerosis (MS) several approaches have been tested already in clinical trials or are currently ongoing with the aim to inhibit myelin-reactive immune responses. Areas covered: This article provides an overview of the recent and ongoing strategies to inhibit specific immune responses in MS, including different applications of myelin peptide-based approaches, T-cell vaccination, DNA vaccination and antigen-coupled cells. Expert opinion: Despite difficulties in translation of antigen-specific therapies in MS, novel approaches have the potential to effectively induce immune tolerance and ameliorate the disease. To improve efficacy of treatments, future trials should include patients in the early phases of the disease, when the autoimmune response is predominant and immune reactivity still focused. The target antigens are not fully defined yet, and robust immunomonitoring assays should developed to provide mechanistic proof of concept in parallel to showing efficacy with respect to inhibiting inflammatory disease activity in the central nervous system (CNS).
\end{abstract}

DOI: https://doi.org/10.1517/13543784.2014.844788

Posted at the Zurich Open Repository and Archive, University of Zurich

ZORA URL: https://doi.org/10.5167/uzh-85433

Journal Article

Accepted Version

Originally published at:

Lutterotti, A; Martin, R (2014). Antigen-specific tolerization approaches in multiple sclerosis. Expert Opinion on Investigational Drugs, 23(1):9-20.

DOI: https://doi.org/10.1517/13543784.2014.844788 


\section{Antigen-Specific Tolerization Approaches in Multiple Sclerosis}

Andreas Lutterotti* and Roland Martin $\S$

* Clinical Department of Neurology, Innsbruck Medical University, Austria.

$\S$ Neuroimmunology and Multiple Sclerosis Research, Department of Neurology, University Hospital Zürich, Switzerland

corresponding author: Roland Martin, MD

Neuroimmunology and Multiple Sclerosis Research (nims)

Department of Neurology, University Hospital Zurich

Frauenklinikstrasse 26

8091 Zürich, Switzerland

Email: roland.martin@usz.ch

Tel.: +41442551125

Fax.: + 41442558864 


\begin{abstract}
Introduction: Inhibition of self-reactive T cells through induction of antigen-specific immune tolerance holds the promise of effective treatment of autoimmune pathology with few side effects and preservation of normal immune functions. In multiple sclerosis (MS) several approaches have been tested already in clinical trials or are currently ongoing with the aim to inhibit myelin-reactive immune responses.

Areas covered: We will give an overview of recent and ongoing strategies to inhibit specific immune responses in MS, including different applications of myelin peptide-based approaches, T cell vaccination, DNA vaccination and antigen-coupled cells. Expert opinion: Despite difficulties in translation of antigen-specific therapies in MS, novel approaches have the potential to effectively induce immune tolerance and ameliorate the disease. To improve efficacy of treatments, future trials should include patients in the early phases of the disease, when the autoimmune response is predominant and immune reactivity still focused. The target antigens are not fully defined yet, and robust immunomonitoring assays should developed to provide mechanistic proof-of-concept in parallel to showing efficacy with respect to inhibiting inflammatory disease activity in the central nervous system (CNS).
\end{abstract}




\section{Introduction:}

Targeted inhibition of antigen-specific T cells can be viewed as the most direct and specific means of correcting pathogenic immune responsiveness, which underlies many organ-specific autoimmune diseases [1-3]. The main goal of such approaches is to stop or reverse an autoreactive $\mathrm{T}$ cell response by specifically inducing immune tolerance to the target selfantigens. Compared to unspecfic immunomodulatory or immunsuppressive interventions, antigen-specific therapies have the advantage that they should in principle only affects the pathogenic immune response without altering physiological immune responsiveness.

Extensive pre-clinical research on basic mechanisms of autoimmunity and immune tolerance facilitated translation of several therapeutic approaches in patients with autoimmune disease in general and multiple sclerosis (MS) in particular. Although the etiology of MS is as yet not fully understood, all current therapeutic approaches are based on the concept that the disease is driven by an immune response directed against self-antigens in the central nervous system (CNS) [4]. Based on extensive research in the animal model of MS, experimental autoimmune encephalomyelitis (EAE), and the fact that the HLA-DR15 haplotype confers most of the genetic risk to develop MS, it has long been considered the prototype of a CD4+ T cell-mediated disease [4]. However, there is increasing evidence for a role of several other compartments of the immune system including CD8+ T cells, B cells/antibodies, and cytokines/chemokines. Despite these data, there is little doubt that CD4+ T cells play a central role in orchestrating the pathogenic immune response in MS patients, and they are consequently viewed as important target for therapeutic intervention. Also, while the armamentarium of approved therapies for MS, which includes small molecule drugs, monoclonal antibodies and other biologics (peptidic compounds, interferon-beta) has grown substantially in the last two decades, and these therapies offer moderate to high efficacy, all inhibit the immune response in an unspecific manner,require long-termapplication and are associated with sometimes serious- to life-threatening risks. Targeting the pathogenic 
autoreactive $\mathrm{T}$ cell response by direct intervention offers the opportunity to treat the disease with few side effects and has the potential for long-lasting clinical benefit, since it aims to correct the causes of autoimmune diseases at their roots. Approaches that aim at a specific inhibition of autoreactive T cells are subject of this review.

\subsection{Principles of antigen-specific / T cell mediated therapies}

Reactivity against self is inherent to the function of the adaptive arms of the immune system, i.e. antibodies and $\mathrm{T}$ cells, and under physiological conditions multiple safeguards avoid that high affinity and pathogenic autoantibodies or autoreactive T cells develop. Hence, pathogenic autoimmunity is avoided at several developmental steps, first in the thymus (central tolerance), where thymocytes are eliminated by clonal deletion if they recognize selfHLA together with self-peptides with high avidity [5]. It is important to note that despite this first checkpoint, where high avidity self-reactive $\mathrm{T}$ cells are eliminated, those that are positively selected and constitute the peripheral $\mathrm{T}$ cell repertoire have all been selected on self-HLA/self-peptide complexes, which means that they all are in principle autoreactive. Therefore, further safeguard mechanisms are required to maintain immunologic tolerance at the level of peripheral immune activation. All therapeutic strategies aiming to induce antigenspecific tolerance operate at the level of peripheral tolerance, since it is not possible to influence central tolerance mechanisms. Antigen-presentation and activation of autoreactive effector $\mathrm{T}$ cells are the main processes, which are targeted by tolerization approaches. The most essential process in the activation of an effector $\mathrm{T}$ cell is the formation of the immune synapse between the T cell and an APC (Figure). This highly specific interaction requires formation of the trimolecular complex (signal 1), engaging the HLA class II molecule of the APC, the antigenic peptide bound to the HLA class II molecule and the T cell receptor (TCR). Formation of a stable immune synapse is further dependent on the interaction of different molecules between the APC and the T cell, which can have both stimulatory or 
inhibitory effects (signal 2). Peripheral tolerance can act at different levels in the formation of the immune synapse (Figure). In the absence of costimulatory signals, i.e. signal 2, upon engagement of the trimolecular complex a $\mathrm{T}$ cells is rendered unresponsive to antigen stimulation, a state that is referred to as anergy [6]. Anergy can persist even if the antigen is later presented by a fully competent APC, however it is in principle transient and reversible and can be overcome by interleukin-2 [7,8]. Engagement of a negative second signal pathway between the APC and the T cell (eg CTLA4/CD80 or CD86, PD1/PD1L) leads to clonal deletion through apoptosis of T cells [9-11]. Overactivation of the TCR in a pre-activated T cell might lead to apoptosis of the T cell by activation induced cell death (AICD), via the interaction of FasLigand with Fas [12-14].

Besides the above direct means of functionally silencing or eliminating an autoreactive $\mathrm{T}$ cell, autoreactivity can also actively be suppressed by indirect mechanisms that involve regulatory T cells (Tregs) [15-17], and the latter cells have also been employed for tolerization approaches [18]. Neither Tregs nor any of the other abovementioned mechanisms usually maintains peripheral tolerance alone. Instead it is more likely that these act in concert and probably need to be broken at several levels before overt autoimmune diseases develop. Also, while mechanisms like anergy, insufficient- or too strong activation are supposedly more important for an early reduction in pathogenic $\mathrm{T}$ cell responses, the induction of Treg has the potential to lead to a long-term and stable inhibition of pathogenic, autoreactive $\mathrm{T}$ cell responses [19]. Furthermore, alterations in the cytokine milieu with the aim to skew the effector subsets from a proinflammatory (ie. TH1, TH17) to an anti-inflammatory phenotype (TH2, Tr1), a process referred to as immune deviation, can lead to the induction and maintenance of immune tolerance [20].

\section{Previous and current approaches of antigen-specific therapies in MS}


While the basic mechanisms of $\mathrm{T}$ cell tolerance involve the interaction with the trimolecular complex or induction of regulatory cell and/or cytokine responses the approaches used to achieve this inhibition of $\mathrm{T}$ cells differ in their methods as well as the route of administration (Figure). Many approaches focused on the specific self-peptide as the central structure of the trimolecular complex responsible for a stable interaction between the HLA and the TCR. When using synthetic peptides different routes of administration have been shown to induce tolerance. In MS, clinical trials were performed with mucosal, intravenous, sub-, intra- or epicutaneous application of peptides, which derived mostly from peptides of myelin basic protein (MBP) but also of other myelin proteins including myelin oligodendrocyte protein (MOG) and proteolipid protein (PLP) (Table). A different strategy relied on synthetic peptides, which had been modified in their interacting regions, i.e. altered peptide ligands (Table). As opposed to myelin peptides the TCR of a pathogenic myelin-specific T cell population can also be used as target structure, either through administration of peptides corresponding to regions of the complementarity determining region of TCRs or injection of attenuated pathogenic myelin-specific T cells (Table). Both approaches have been tested in clinical trials in MS patients. Finally intravenous infusion of autologous, antigen-coupled cells is a novel approach currently tested for treatment of MS.

\subsection{Myelin peptide-based approaches to induce tolerance in MS}

\subsubsection{Mucosal administration of myelin peptides}

Induction of tolerance via oral or mucosal administration of peptides is an appealing approach not only because of advantages for patients with regard to applicability but also with regard to its favorable safety profile in preclinical studies [20]. The immunologic mechanisms of oral tolerance involve clonal anergy or deletion when given at a high dose whereas low dose treatment leads to bystander suppression through the release of suppressive cytokines, such as TGF- $\beta$, IL-4 or IL-10 by regulatory T cells [21]. However, despite promising results in 
preclinical models, both clinical phase I/II trials as well as a large phase III placebo-controlled trial with oral bovine MBP in 515 MS patients failed [22]. Nevertheless, discussion is still ongoing as to whether dosage or formulation of myelin might have influenced efficacy of the treatment and whether an unusually strong placebo effect in the phase III trial has contributed to the negative outcome of the phase III trial.

\subsubsection{Intravenous administration of myelin peptides}

An alternative approach has been the intravenous administration of peptides at high doses, with the aim to induce activation-induced cell death (AICD) in antigen-specific T cells. In phase I/II clinical trials soluble MBP peptide (MBP82-96) was well tolerated and showed favorable effect on disease progression in HLA-DR2-positive patients [23,24]. Based on these results a multicenter, randomized, double-blind, placebo-controlled, phase III trial was performed in 612 SPMS patients stratified for HLA-DR2 and HLA-DR4. MBP peptide (500 mg) was administered i.v. every 6 months [25]. The trial failed to reach both the primary outcome, i.e. time to confirmed disability progression, or other secondary outcomes. No safety issues occurred, and the peptide was well tolerated. Immunological analyses from these patients have not been reported. Altogether further development of the approach has been stopped. Possible reasons for the failure of the strategy include the target population and the trial design. From the clinical perspective, induction of immune tolerance in MS will always remain a preventive measure. Thus, inclusion of patients with longer disease duration, who are in a phase of the disease where the autoimmune pathology might be less important, might have biased the results, since measures of neurodegeneration might not be the right outcome parameter. Another reason for the failure might have been the use of a single peptide.

Although, the primary target antigen in MS is not known for certain, it is likely that several target antigens from different myelin proteins exist and that these might differ between 
patients and even change over time in individual patients. Analysis of peptide specific immune responses might have helped in the interpretation of the data.

Intravenous injection of a solubilized MHC-peptide complex was used in another approach to induce antigen-specific tolerance, however, although the administration of the solubilized MHC-MBP84-102 complex was safe, it did not show a significant treatment effect in patients with SP-MS [26]. The latter group of patients was probably not the right target population for the study, which underscores the importance of choosing a proper trial design for such early proof-of-concept trials.

In a similar strategy, recombinant single chain, two domain MHC class II molecules covalently coupled to peptides were developed. For the treatment of MS a RTL (RTL1000) was developed, in which the immunodominant MOG35-55 peptide was covalently bound to the $\beta 1-\alpha 1$ domains of HLA-DR2. RTL1000 was tested in MS patients in a multicenter, double blind, phase I dose dose finding study study with the aim to determine the maximum tolerated does of a single iv. injection of RTL1000 [27]. Thirty-four MS patients were treated with increasing doses of RTL1000 or placebo and the study drug was well tolerated up to a dose of $60 \mathrm{mg}$. Overall there was no increase in disease activity. In EAE a similar dose, based on body surface area, was effective in prevention and treatment of DR2 transgenic mice with MOG35-55 induced EAE [28]. The company is currently preparing a phase II trial in MS and announced further development of this approach in other autoimmune disease like celiac disease, uveitis and rheumatoid arthritis.

\subsubsection{Subcutaneous/intradermal administration of myelin peptides}

Administration of a mix of 4 synthetic myelin peptides (ATX-MS-1467, Apitope Technology

Ltd, licensed by MerckSerono) derived from MBP has been tested in 6 secondary progressive MS patients [29]. ATX-MS-1467 is currently being tested in a second phase I study in 40 RRMS patients (ClinicalTrials.gov Identifier: NCT01097668) assessing the safety of the 
approach and comparing intradermal versus subcutaneous route of administration. The approach is based on the concept that the synthetic peptides induce a strong regulatory $\mathrm{T}$ cell response via IL-10- producing T cells. The approach offers the advantage of using a set of 4 myelin peptides derived from MBP, however does not include peptides from other myelin proteins.

\subsubsection{Epicutaneous administration of myelin peptides}

Recently, transdermal administration of a mixture of three myelin peptides (MBP 85-99, MOG 35-55, PLP139-151) has been tested in a phase II placebo-controlled trial in thirty RRMS patients [30]. Patients were randomized to receive placebo or two doses of peptide mixture ( $1 \mathrm{mg}$ of each peptide vs $10 \mathrm{mg}$ of each peptide). The primary endpoint was the cumulative number of contrast enhancing lesions on MRI in the $1 \mathrm{mg}$ treatment group compared to placebo. The trial met the primary endpoint in showing a reduction in MRI parameters of inflammatory disease activity in patients treated with $1 \mathrm{mg}$ of each peptide compared to placebo. This was paralleled by a reduction in the annualized relapse rate in the treatment group. The $10 \mathrm{mg}$ treatment group did not differ from the placebo group with regard to primary and secondary outcome parameters, but the authors claim that the low number of patients treated with the $10 \mathrm{mg}$ dose precluded statistical analysis. Intriguingly, immunological effects have been reported, showing reduction in myelin-specific $\mathrm{T}$ cell responses in peptide-treated patients compared to placebo and induction of $\operatorname{Tr} 1$ cells [31]. Moreover, histological analyses from skin biopsies at the site of application and samples from draining local lymph nodes revealed activated dendritic Langerhans cells in the skin and a population of granular dendritic cells in local lymph nodes. In summary, this is a promising approach given the easy applicability of the peptide product. Beneficial clinical effects are underscored by mechanistic studies suggesting induction of immune tolerance. 


\subsubsection{Altered peptide ligands}

Altered peptide ligands (APL) are analogues of immunogenic peptides that have been modified by introducing one or few substitutions in amino acid positions essential for contact with the TCR but retain the MHC binding motif moieties. APLs can block T cell responses acting as partial agonists, antagonists or, as it has been demonstrated in an animal model of MS, by inducing a new T cell population with a Th2 phenotype that cross recognizes the native auto-antigen and mediates bystander suppression $[32,33]$. Based on these evidences a MRI- controlled phase II trial in MS with an APL derived from the immunodominant MBP peptide 83-99 was started. However, the trial had to be halted because 3 of 8 patients receiving high dose APL developed relapses [34]. The exacerbations were characterized by inflammatory disease activity on MRI, which was unusual with respect to the number of new inflammatory lesions or the size of lesions when comparing them to those during the patients previous disease history. Extensive analysis of myelin-reactive T cells demonstrated that the observed relapses were paralleled by a strong increase in the frequency of MBP83-99 reactive T cells in the peripheral blood and CSF. Furthermore, most APL- or MBP 83-99-specific T cells that were isolated during relapse had a proinflammatory phenotype and cross-reacted with the respective other peptide, which strongly indicated that APL immunization had expanded proinflammatory MBP 83-99-specific T cells and led to the clinical relapses. This result provides the so far strongest proof of concept in MS, that clonally expanded MBPspecific T cells are able to induce inflammatory lesions in the CNS [34]. A much larger, placebo-controlled, multicenter trial with the same APL that compared 3 different doses and placebo was suspended because of the data from the above trial and hypersensitivity reactions in $9 \%$ of the patients. Differently from the first trial no increases in relapses have been observed and a reduction in the mean number of contrast-enhancing lesions as well as a tendency towards induction of Th2 cells have been reported $[35,36]$. While the exact reasons for the failure of the first APL trial remain unclear, a) the probably too high dose of peptide 
(50 $\mathrm{mg}$ s.c. weekly), b) the injection via an in principle immunogenic route, i.e. subcutaneously, and c) the unusual HLA-class II composition of the small group of patients with very few expressing HLA-DR15, probably all contributed.

\subsection{DNA vaccination}

The principle of this tolerization strategy is a heterotopic expression of a specific target antigen with the aim to induce antigen-specific tolerance. A DNA vaccine of whole human MBP protein (BHT-3009, Bayhill Therapeutics) was chosen as target antigen $[37,38]$. In practice, a plasmid encoding the auto-antigen is injected intramuscularly, which leads to lowlevel expression of the antigen in muscle cells. The intramuscular application of BHT-3009 was well tolerated and provided favorable trends regarding MRI data in MS patients with active disease [39]. This effect was paralleled by a marked decrease in peripheral blood Th1 CD4+ T cells reacting against peptides from the three myelin proteins MBP, MOG and PLP and reduced titers of specific auto-antibodies in CSF to MBP but also PLP [39]. In a phase II trial in 267 RR-MS patients were randomized to receive either placebo or two doses of BHT3009 [40]. Treatment with BHT-3009 reduced the rate of new enhancing lesions during weeks 28 to 48 , but did not meet this primary endpoint. A recent post-hoc analysis suggested a protective effect of the low-dose BHT3009 $(0.5 \mathrm{mg})$ on the evolution of new lesions to persistent black holes, which are thought to represent irreversible brain damage [41]. As an advantage compared to other tolerization strategies DNA vaccine offers the opportunity to combine expression of the auto-antigen with expression of anti-inflammatory cytokines in a single plasmid, which might enhance the efficacy. The strategy has succsesfully been tested in Type I Diabetes mellitus patients with a DNA vaccine encoding pro-insulin [42].

\subsection{T cell receptor vaccination}


This approach involves administration of either attenuated autologous antigen-specific $\mathrm{T}$ cells or peptides from the complementarity determining regions (CDR) 2 or 3 of myelin reactive $\mathrm{T}$ cells with the aim to induce an immune response directed against these pathogenic T cells. Several studies tested T cell vaccination for treatment of MS using autologous myelin peptide-specific, attenuated T cells derived from peripheral blood lymphocytes or CSF [4351]. Overall, the treatment was well tolerated in MS patients. A reduction in the frequency of myelin-reactive $\mathrm{T}$ cells has been reported as well as a reduction in disease activity in several patients. Based on these encouraging results a randomized, double blind trial of autologous attenuated myelin-specific T cells has been performed in 26 relapsing-progressive MS patients receiving repeated subcutaneous administration of $1 \times 10^{6}$ attenuated myelin-specific $\mathrm{T}$ cells and compared 7 patients treated with sham injections [52]. T cells were derived from peripheral blood lymphocytes, which were stimulated with 9 myelin peptides from three proteins (MBP, MOG and PLP). The study demonstrated feasibility and safety of the approach and indicated significant efficacy on clinical parameters of disability as well as inflammatory disease activity in the treated group as compared to the sham treated patients. However, there was no difference in MRI parameters of disease activity. A randomized, placebo controlled, phase $2 \mathrm{~b}$ trial using peripheral blood-derived myelinspecific T cells, in-vitro expanded with six myelin peptides from MBP, MOG and PLP (Tovaxin ${ }^{\circledR} /$ Tcelna $^{\mathrm{TM}}$; Opexa Therapeutics Inc.) was conducted in 150 RRMS and CIS patients [49]. Over 12 months the study drug was safe and well tolerated. Overall, there was no difference in the clinical and MRI parameters of efficacy, although a subgroup analysis suggested a benefit for Tovaxin ${ }^{\circledR}$ in treatment-naïve patients with high disease activity at baseline. Based on an open label dose escalation study showing favorable effects of Tovaxin on clinical and immunological parameters according to a press release by the company, Tcelna $^{\mathrm{TM}}$ (licensed by MerckSerono) has been granted Fast Track designation by the U.S. FDA for the secondary progressive MS indication [50]. 
Therapeutic vaccination using peptides from the CDR of myelin-reactive T cells from MS patients is a different approach aiming at modulation of autoreactivity. Administration of TCR peptides via monthly intramuscular injection has been tested in a double-blind pilot trial in $23 \mathrm{MS}$ patients [53]. Six of the patients were responders to the therapy showing progression-free disease over 1 year, reduced MBP-specific T cell responses and induction of IL-10. For further development of the approach, three peptides from TCR BV genes have been identified as best candidate targets out of approximately $1000 \mathrm{AV}$ and BV genes from neuroantigen-specific T cells from $200 \mathrm{MS}$ patients [54]. Intramuscular injection of the vaccine containing three CDR2 peptides (NeuroVax, Immune Response Biopharma Inc) has been tested in an open label study in 27 MS patients by monthly intramuscular injection over a period of 12 months. Following vaccination most patients remained stable with regard to disability, and a high frequency of IL10-secreting T cells could be measured in treated patients. This was paralleled by increased expression of FoxP3 in $\mathrm{CD} 4+\mathrm{CD} 25+$ regulatory $\mathrm{T}$ cells. The company recently announced a randomized, double-blind, multicenter, active controlled, parallel group study to assess the efficacy and safety of weekly intramuscular injection of NeuroVax compared to weekly Interferon-beta 1a i.m. in patients with MS..

\subsection{Antigen-coupled cell tolerance}

A tolerization strategy, which looks very promising based on extensive experience in various animal models $[8,19,55-67]$ uses autologous peripheral blood mononuclear cells (PBMC) pulsed with myelin peptides and chemically fixed with the cross linker 1-ethyl-3-(3dimethylaminopropyl)-carbodiimide (EDC), as tolerogenic vaccine. In experimental autoimmune encephalomyelitis (EAE) this protocol not only prevented disease, but even effectively reduced the onset and severity of all subsequent relapses when given after disease induction, indicating that specific tolerance can downregulate an ongoing autoimmune response [68]. This regimen has also been shown to prevent epitope spreading and has proven 
excellent efficacy in animal models of different $\mathrm{T}$ cell-mediated autoimmune diseases, transplantation tolerance and allergy $[19,69]$.

A first -in-man trial (ETIMS trial) was conducted in MS patients with the aim to assess the feasibility, safety and tolerability of this novel tolerization regimen, which employs a single infusion of autologous peripheral blood mononuclear cells chemically coupled with seven myelin peptides (MOG1-20, MOG35-55, MBP13-32, MBP83-99, MBP111-129, MBP146170 and PLP139-154). In the open-label, single center, dose escalation study, nine MS patients (7 relapsing-remitting and 2 secondary progressive; EDSS 1-5.5), who were offtreatment for standard therapies were treated with a single infusion of ETIMS product. All patients had to show $\mathrm{T}$ cell reactivity against at least one of the myelin peptides used in the trial. Neurological, MRI, laboratory and immunological examinations were performed to assess the safety, tolerability and in vivo mechanisms of action of this regimen. Overall, administration of antigen-coupled cells was feasible, had a favorable safety profile and was well tolerated in MS patients. Compared to the pre-treatment observation period there was no increase in clinical and MRI parameters of disease activity by this regimen. Patients receiving the high dose $\left(>1 \times 10^{9}\right)$ of peptide-coupled cells showed a decrease in antigen-specific $\mathrm{T}$ cell responses following ETIMS therapy [70]. A multicenter phase IIa trial assessing efficacy and safety of ETIMS therapy in early RRMS patients is currently in preparation. Advantages of the approach are that tolerance can be simultaneously induced to multiple epitopes, thereby targeting both naïve and activated autoreactive T cells with multiple specificities. Further, invivo the regimen has proven to block epitope spreading efficiently and relapses can be inhibited by tolerance to the spread epitope. From preclinical studies it is expected that a single intravenous infusion of peptide-coupled PBMC is able to induce long-term amelioration. Antigen coupled cell tolerance adds a completely new mechanism of tolerance to the field. There is evidence that at least two distinct mechanisms are involved, including 1) direct tolerance through failure of costimulation in $\mathrm{T}$ cells encountering antigen/MHC 
complexes on chemically-fixed antigen presenting cells (APC) [8], and 2) an indirect mechanism, through processing of antigens from EDC treated apoptotic cells by host APCs and re-presentation in a tolerogenic way $[67,71]$ (Figure 1).

\subsection{Summary}

Several approaches aiming at antigen specific tolerance in MS have already been successfully tested in patients, with regard to safety of the treatment and immunological measures of immune tolerance. Only few approaches failed because of safety issues. However, with regard to clinical efficacy a major breakthrough has not been reached, yet. Further improvements in ongoing and future strategies can be made in the selection and range of target antigens, the immunological measures of immune reactivity and tolerance, but also in patient selection and trial design. Besides the above mentioned therapeutic strategies, which reflect the most important developments in the field, several novel and promising strategies are already in preclinical development including the use of tolerogenic dendritic cells [72].

\section{Expert Opinion}

Despite many successes in animal models of MS and also other autoimmune diseases the translation of antigen-specific therapies to MS patients or in general to organ-specific autoimmune diseases resulted in several difficulties including lack of efficacy, or even disease exacerbation and hypersensitivity reactions. In our opinion, the pitfalls do, however, not only lie in clinical outcomes of safety and efficacy but also various immunological and conceptual aspects.

\subsection{Target antigens}

Over the last decades many groups have studied the immune response in MS patients [4].

Given the histopathologic evidence of a primary immune-mediated destruction of myelin with 
relative sparing of axons in lesions of MS patients antigens within the myelin sheath were thought to be the main targets of the immune response [73]. Thus, many researchers have focused on myelin-specific T cell responses in MS patients. Extensive research in animal models of MS supports the concept that the pathogenic immune response is primarily directed against myelin antigens. Consequently, research devoted most attention to the main myelin proteins MBP PLP, MOG, but also included CNPase, MOBP, OSP, and to a minor extent non-myelin proteins such as $\alpha \mathrm{B}$-crystallin and neuronal antigens [4]. Despite these efforts, a single target antigen could not be identified yet in MS, and several reasons may account for this fact. First, it is likely that the target antigen/s differ/s between patients depending on their HLA-class II background and other factors, and there is at least some evidence also in humans that it changes over time due to epitope spreading [74-76]. In EAE epitope spreading has been analyzed in detail and it could be shown that chronic demyelination leads to the generation of new $\mathrm{T}$ cell responses against multiple endogenous antigens and that these newly generated $\mathrm{T}$ cells are able to induce relapses [77,78]. Moreover, induction of tolerance against the spread epitope results in inhibition of further relapses [77]. Even though the evidence for epitope spreading is less solid in MS than in the EAE model, it has been demonstrated that the repertoire of activated $\mathrm{T}$ cells changes during the course of the disease [74-76]. Therefore tolerization against myelin antigens in MS should be pursued early in the disease course and should target both naïve and activated autoreactive cells specific for multiple different antigens.

Second, several different assays have been used to analyze myelin-specific $\mathrm{T}$ cell responses in MS, the most common analyzing either proliferation response or cytokine secretion. These assays vary considerably in the concentrations of antigens used or the number of $\mathrm{T}$ cells applied in the assay. Both these factors have to be considered in the interpretation of the data. Very high concentration of antigen can facilitate an immune response mediated by low avidity autoreactive T cells, which potentially reflect $\mathrm{T}$ cells with some degree of cross- 
reactivity against myelin antigens, but higher avidity for different antigens. These crossreactive T cells are unlikely to be related to the primary autoimmune processes in MS [79]. Lower concentrations of antigen might be more appropriate to identify myelin-reactive $\mathrm{T}$ cells with a high avidity for the target antigens, which are more likely to reflect a pathogenic immune response [79]. Myelin reactivity can be found in many healthy controls and the difference between MS and healthy controls might lie in the avidity and phenotypic characteristics of $\mathrm{T}$ cells. Further, the precursor frequencies of myelin-reactive $\mathrm{T}$ cells vary considerably across different studies and depending on which readouts have been used. The latter issue, i.e. the development and application of standardized and well-validated tests to measure the frequency and phenotype of autoantigen-specific $\mathrm{T}$ cells reliably over time in a single patient and groups of patients is a major and as yet not fully resolved problem. Many factors need to be considered in this context, and further development is clearly needed to improve suitable ex vivo readouts to prove the biological effect of tolerization approaches. For future trials it will be essential to provide validated and robust assays to assess antigenspecific $\mathrm{T}$ cell responses, their frequencies and functional phenotypes.

Although CD4+ T cells are considered to be crucial in orchestrating the pathogenic immune response in MS, it is likely that several other compartments of the immune system add to the autoreactive inflammation. The discovery of anti aquaporin4 antibodies (AQP4-Ab) in neuromyelitis optica demonstrated the importance of humoral and B cell mediated immune responses in a demyelinating disease [80]. An important role of B cell-mediated effector functions in MS has also been supported by clinical trials demonstrating efficacy of B cell directed therapies in RRMS patients [81]. Recently, antibodies against Kir4.1, a potassium channel, have been described in MS patients [82]. Thus, future tolerization strategies in MS should assess their efficacy in reducing both $\mathrm{T}$ and $\mathrm{B}$ cell mediated immune responses, as well as other immune compartments. Consequently, the search for biomarkers able to reflect induction of immune tolerance throughout different immune compartments through a specific 
tolerance signature will be essential not only for a better understanding of the treatment effects but also the pathogenesis of the disease.

In summary, although a single target antigen could not be identified in MS the evidence for myelin proteins as importat targets of the autoimmune response is fairly robust across different studies in several cohorts of MS patients. Given the possibility that the target antigens differ between patients and may even change throughout the disease, because of epitope spreading, tolerization strategies, which offer the possibility $\mathrm{t}$ target various antigens at the same time are more likely to be successful in MS.

\subsection{Patient population and trial design}

Many trials, which tested new antigen-specific therapies in MS, included progressive patients with long-standing disease course, However, at later stages of the disease, antigen-specific autoimmune inflammation might be less relevant than during the earlier stages of the disease, and patients in the progressive phase of the disease are usually not amenable to any of the currently available treatments. Hence, trying to provide proof-of-concept and show efficacy in the progressive stage is difficult if not impossible, and several of the above approaches were unfortunately mainly tested in progressive patients. Further, as already mentioned above it is likely that the specific immune response spreads to several antigens during the disease.

Consequently, in future therapeutic trials aiming at antigen-specific tolerance it will be crucial to start treatment early in RR-MS patients, ideally within the first five years from onset of the disease. Patients should be tested for their reactivity before inclusion in the trial, and this should be a pre-requisite for treatment to follow its immunological effects. Clinical trials should be accompanied by appropriate mechanistic studies to measure the effect of the treatment on the immune system, not only as a relevant safety parameter but also as a measure of biological effect, i.e. if antigen-specific tolerance has indeed been induced. The proof-ofconcept that induction of tolerance against specific antigens is able to halt the disease will 
only be possible by efficient combination of immunologic and clinical/MRI based outcome parameters. For several tolerization strategies we further expect that they will at least in part depend on the specific HLA-class II background of individuals. Thus, the HLA-class II type of enrolled patients has to be analyzed and taken into consideration in the interpretation of the data.

Early phase trials in RRMS aiming to assess safety and preliminary efficacy should include MRI as relevant outcome parameter. Since clinical efficacy can only be judged by large-scale phase IIb and III trials, which require large patient numbers and long study periods, MRI measures are considered the best validated biomarkers and are the recommended outcome measure for mechanism of action-oriented phase II clinical trials [83,84]. MRI parameters are ideal for correlating inflammatory activity in the CNS with immunological parameters reflecting the mechanism of action of the therapy. Obtaining serial and longitudinal MRI data also serves as a sensitive safety measure [34].

\section{Conclusion}

In summary, induction of immune tolerance in pathogenic $\mathrm{T}$ cells remains the only therapeutic strategy with the potential to treat autoimmune disease at its roots and thus being able to cure the disease. Despite the fact that several attempts in MS patients failed due to either side effects or lack of efficacy, novel strategies hold the promise that the goal of immune tolerance can still be reached. Several key point have to be considered in future clinical development of such approaches. First, strategies should aim to induce tolerance to several myelin epitopes simultaneously. Second, future clinical trials should focus on patients early in the disease, when autoreactive inflammation is predominant and epitope spreading still limited. Third, robust immunological assays should be developed to follow antigenspecific $\mathrm{T}$ cells in treated patients, measure immunological outcome parameters, and provide information on the mechanism of action of therapy and immune tolerance. 


\section{References}

1. Steinman L: Inverse vaccination, the opposite of jenner's concept, for therapy of autoimmunity. Journal of internal medicine 267(5):441-451.

2. Dolgin E: The inverse of immunity. Nat Med (2010) 16(7):740-743.

3. Lutterotti A, Sospedra M, Martin R: Antigen-specific therapies in ms - current concepts and novel approaches. $J$ Neurol Sci (2008) 274(1-2):18-22.

4. Sospedra M, Martin R: Immunology of multiple sclerosis. Annu Rev Immunol (2005) 23(683-747.

5. Goverman JM: Immune tolerance in multiple sclerosis. Immunol Rev (2011) 241(1):228-240.

6. Schwartz RH: T cell anergy. Annu Rev Immunol (2003) 21(305-334.

7. Jenkins MK, Mueller D, Schwartz RH, Carding S, Bottomley K, Stadecker MJ, Urdahl KB, Norton SD: Induction and maintenance of anergy in mature t cells. Adv Exp Med Biol (1991) 292(167-176.

8. Jenkins MK, Schwartz RH: Antigen presentation by chemically modified splenocytes induces antigen-specific t cell unresponsiveness in vitro and in vivo. $J$ Exp Med (1987) 165(2):302-319. 
9. Krummel MF, Allison JP: Ctla-4 engagement inhibits il-2 accumulation and cell cycle progression upon activation of resting t cells. $J$ Exp Med (1996) 183(6):25332540.

10. Walunas TL, Lenschow DJ, Bakker CY, Linsley PS, Freeman GJ, Green JM, Thompson $\mathrm{CB}$, Bluestone JA: Ctla-4 can function as a negative regulator of $\mathbf{t}$ cell activation. Immunity (1994) 1(5):405-413.

11. Fife BT, Bluestone JA: Control of peripheral t-cell tolerance and autoimmunity via the ctla-4 and pd-1 pathways. Immunol Rev (2008) 224(166-182.

12. Mueller DL: Mechanisms maintaining peripheral tolerance. Nat Immunol (2010) 11(1):21-27.

13. Alderson MR, Tough TW, Davis-Smith T, Braddy S, Falk B, Schooley KA, Goodwin RG, Smith CA, Ramsdell F, Lynch DH: Fas ligand mediates activation-induced cell death in human t lymphocytes. $J$ Exp Med (1995) 181(1):71-77.

14. Kabelitz D, Janssen O: Antigen-induced death of t-lymphocytes. Frontiers in bioscience : a journal and virtual library (1997) 2(d61-77.

15. von Boehmer H, Melchers F: Checkpoints in lymphocyte development and autoimmune disease. Nat Immunol (2010) 11(1):14-20.

16. Rudensky AY: Regulatory t cells and foxp3. Immunological reviews (2011) 241(1):260-268. 
17. Sakaguchi S, Yamaguchi T, Nomura T, Ono M: Regulatory t cells and immune tolerance. Cell (2008) 133(5):775-787.

18. von Boehmer H, Daniel C: Therapeutic opportunities for manipulating t(reg) cells in autoimmunity and cancer. Nature reviews Drug discovery (2013) 12(1):51-63.

19. Miller SD, Turley DM, Podojil JR: Antigen-specific tolerance strategies for the prevention and treatment of autoimmune disease. Nat Rev Immunol (2007) 7(9):665-677.

20. Weiner HL, Friedman A, Miller A, Khoury SJ, al-Sabbagh A, Santos L, Sayegh M, Nussenblatt RB, Trentham DE, Hafler DA: Oral tolerance: Immunologic mechanisms and treatment of animal and human organ-specific autoimmune diseases by oral administration of autoantigens. Annu Rev Immunol (1994) 12(809837.

21. Faria AM, Weiner HL: Oral tolerance. Immunol Rev (2005) 206(232-259.

22. Weiner HL, Mackin GA, Matsui M, Orav EJ, Khoury SJ, Dawson DM, Hafler DA: Double-blind pilot trial of oral tolerization with myelin antigens in multiple sclerosis. Science (1993) 259(5099):1321-1324.

* One of the first tolerization trials in MS. Patients receiving oral boine myelin or control antigen were analysed for cinical efficacy and immunological parameters.

23. Warren KG, Catz I, Ferenczi LZ, Krantz MJ: Intravenous synthetic peptide mbp8298 delayed disease progression in an hla class ii-defined cohort of patients with progressive multiple sclerosis: Results of a 24-month double-blind placebo- 
controlled clinical trial and 5 years of follow-up treatment. Eur J Neurol (2006) 13(8):887-895.

24. Warren KG, Catz I, Wucherpfennig KW: Tolerance induction to myelin basic protein by intravenous synthetic peptides containing epitope p85 vvhffknivtp96 in chronic progressive multiple sclerosis. Journal of the neurological sciences (1997) 152(1):31-38.

25. Freedman MS, Bar-Or A, Oger J, Traboulsee A, Patry D, Young C, Olsson T, Li D, Hartung HP, Krantz M, Ferenczi L et al: A phase iii study evaluating the efficacy and safety of mbp8298 in secondary progressive ms. Neurology (2011) 77(16):1551-1560.

* The paper presents the final results of the phase III trial on intravenous MBP peptide in secondary progressive MS.

26. Goodkin DE, Shulman M, Winkelhake J, Waubant E, Andersson P, Stewart T, Nelson S, Fischbein N, Coyle PK, Frohman E, Jacobs L et al: A phase i trial of solubilized dr2:Mbp84-102 (ag284) in multiple sclerosis. Neurology (2000) 54(7):1414-1420.

27. Yadav V, Bourdette DN, Bowen JD, Lynch SG, Mattson D, Preiningerova J, Bever CT, Jr., Simon J, Goldstein A, Burrows GG, Offner H et al: Recombinant t-cell receptor ligand (rtl) for treatment of multiple sclerosis: A double-blind, placebocontrolled, phase 1, dose-escalation study. Autoimmune diseases (2012) $2012(954739$.

28. Vandenbark AA, Rich C, Mooney J, Zamora A, Wang C, Huan J, Fugger L, Offner H, Jones R, Burrows GG: Recombinant ter ligand induces tolerance to myelin oligodendrocyte glycoprotein 35-55 peptide and reverses clinical and histological 
signs of chronic experimental autoimmune encephalomyelitis in hla-dr2 transgenic mice. J Immunol (2003) 171(1):127-133.

29. http://Www.Apitope.Com/pipeline/ms.Html.

30. Walczak A, Siger M, Ciach A, Szczepanik M, Selmaj K: Transdermal application of myelin peptides in multiple sclerosis treatment. JAMA neurology (2013) 1-6.

31. Jurynczyk M, Walczak A, Jurewicz A, Jesionek-Kupnicka D, Szczepanik M, Selmaj $\mathrm{K}$ : Immune regulation of multiple sclerosis by transdermally applied myelin peptides. Ann Neurol (2010) 68(5):593-601.

* The paper presents the first report on the effects of transdermal application of myelin peptides in MS patients and describes the immunological effects in skin bisopsies and samples from local lymph nodes.

32. Nicholson LB, Greer JM, Sobel RA, Lees MB, Kuchroo VK: An altered peptide ligand mediates immune deviation and prevents autoimmune encephalomyelitis. Immunity (1995) 3(4):397-405.

33. Windhagen A, Scholz C, Hollsberg P, Fukaura H, Sette A, Hafler DA: Modulation of cytokine patterns of human autoreactive $t$ cell clones by a single amino acid substitution of their peptide ligand. Immunity (1995) 2(4):373-380.

34. Bielekova B, Goodwin B, Richert N, Cortese I, Kondo T, Afshar G, Gran B, Eaton J, Antel J, Frank JA, McFarland HF et al: Encephalitogenic potential of the myelin basic protein peptide (amino acids 83-99) in multiple sclerosis: Results of a phase ii clinical trial with an altered peptide ligand. Nat Med (2000) 6(10):1167-1175. 
** The thorough analysis of $\mathrm{T}$ cell responses in patients experiencing clinical exacerbation after treatment with a altered peptide ligand, demonstrated for the first time in humans an association of $\mathrm{T}$ cell response to myelin peptide with inflammation in the brain.

35. Crowe PD, Qin Y, Conlon PJ, Antel JP: Nbi-5788, an altered mbp83-99 peptide, induces a t-helper 2-like immune response in multiple sclerosis patients. Ann Neurol (2000) 48(5):758-765.

36. Kappos L, Comi G, Panitch H, Oger J, Antel J, Conlon P, Steinman L: Induction of a non-encephalitogenic type $2 \mathrm{t}$ helper-cell autoimmune response in multiple sclerosis after administration of an altered peptide ligand in a placebo-controlled, randomized phase ii trial. The altered peptide ligand in relapsing ms study group. Nat Med (2000) 6(10):1176-1182.

37. Ho PP, Fontoura P, Platten M, Sobel RA, DeVoss JJ, Lee LY, Kidd BA, Tomooka BH, Capers J, Agrawal A, Gupta R et al: A suppressive oligodeoxynucleotide enhances the efficacy of myelin cocktail/il-4-tolerizing DNA vaccination and treats autoimmune disease. J Immunol (2005) 175(9):6226-6234.

38. Ho PP, Fontoura P, Ruiz PJ, Steinman L, Garren H: An immunomodulatory gpg oligonucleotide for the treatment of autoimmunity via the innate and adaptive immune systems. J Immunol (2003) 171(9):4920-4926.

39. Bar-Or A, Vollmer T, Antel J, Arnold DL, Bodner CA, Campagnolo D, Gianettoni J, Jalili F, Kachuck N, Lapierre Y, Niino M et al: Induction of antigen-specific tolerance in multiple sclerosis after immunization with DNA encoding myelin basic protein in a randomized, placebo-controlled phase 1/2 trial. Arch Neurol (2007) 64(10):1407-1415. 
* First report of a DNA based vaccination for treatment of a immune mediated disease in humans.

40. Garren H, Robinson WH, Krasulova E, Havrdova E, Nadj C, Selmaj K, Losy J, Nadj I, Radue EW, Kidd BA, Gianettoni J et al: Phase 2 trial of a DNA vaccine encoding myelin basic protein for multiple sclerosis. Ann Neurol (2008) 63(5):611-620.

41. Papadopoulou A, von Felten S, Traud S, Rahman A, Quan J, King R, Garren H, Steinman L, Cutter G, Kappos L, Radue EW: Evolution of ms lesions to black holes under DNA vaccine treatment. Journal of neurology (2012) 259(7):1375-1382.

42. Roep BO, Solvason N, Gottlieb PA, Abreu JR, Harrison LC, Eisenbarth GS, Yu L, Leviten M, Hagopian WA, Buse JB, von Herrath M et al: Plasmid-encoded proinsulin preserves c-peptide while specifically reducing proinsulin-specific cd8+ $\mathbf{t}$ cells in type 1 diabetes. Science translational medicine (2013) 5(191):191ra182.

43. Correale J, Lund B, McMillan M, Ko DY, McCarthy K, Weiner LP: T cell vaccination in secondary progressive multiple sclerosis. J Neuroimmunol (2000) 107(2):130-139.

44. Hafler DA, Cohen I, Benjamin DS, Weiner HL: T cell vaccination in multiple sclerosis: A preliminary report. Clin Immunol Immunopathol (1992) 62(3):307-313.

45. Hermans G, Medaer R, Raus J, Stinissen P: Myelin reactive t cells after t cell vaccination in multiple sclerosis: Cytokine profile and depletion by additional immunizations. J Neuroimmunol (2000) 102(1):79-84. 
46. Medaer R, Stinissen P, Truyen L, Raus J, Zhang J: Depletion of myelin-basic-protein autoreactive $t$ cells by $\mathbf{t}$-cell vaccination: Pilot trial in multiple sclerosis. Lancet (1995) 346(8978):807-808.

47. Van der Aa A, Hellings N, Medaer R, Gelin G, Palmers Y, Raus J, Stinissen P: T cell vaccination in multiple sclerosis patients with autologous csf-derived activated $t$ cells: Results from a pilot study. Clin Exp Immunol (2003) 131(1):155-168.

48. Zhang J, Medaer R, Stinissen P, Hafler D, Raus J: Mhc-restricted depletion of human myelin basic protein-reactive t cells by $\mathbf{t}$ cell vaccination. Science (1993) 261(5127):1451-1454.

49. Fox E, Wynn D, Cohan S, Rill D, McGuire D, Markowitz C: A randomized clinical trial of autologous t-cell therapy in multiple sclerosis: Subset analysis and implications for trial design. Multiple sclerosis (2012) 18(6):843-852.

50. Loftus B, Newsom B, Montgomery M, Von Gynz-Rekowski K, Riser M, Inman S, Garces P, Rill D, Zhang J, Williams JC: Autologous attenuated t-cell vaccine (tovaxin) dose escalation in multiple sclerosis relapsing-remitting and secondary progressive patients nonresponsive to approved immunomodulatory therapies. Clinical immunology (2009) 131(2):202-215.

51. Achiron A, Lavie G, Kishner I, Stern Y, Sarova-Pinhas I, Ben-Aharon T, Barak Y, Raz H, Lavie M, Barliya T, Faibel $\mathrm{M}$ et al: $\mathbf{T}$ cell vaccination in multiple sclerosis relapsing-remitting nonresponders patients. Clinical immunology (2004) 113(2):155-160. 
52. Karussis D, Shor H, Yachnin J, Lanxner N, Amiel M, Baruch K, Keren-Zur Y, Haviv O, Filippi M, Petrou $P$, Hajag $S$ et al: $T$ cell vaccination benefits relapsing progressive multiple sclerosis patients: A randomized, double-blind clinical trial. PloS one (2012) 7(12):e50478.

53. Vandenbark AA, Chou YK, Whitham R, Mass M, Buenafe A, Liefeld D, Kavanagh D, Cooper S, Hashim GA, Offner H: Treatment of multiple sclerosis with t-cell receptor peptides: Results of a double-blind pilot trial. Nat Med (1996) 2(10):1109-1115.

* important trial using T cell receptor peptides for treatment of MS.

54. Bourdette DN, Edmonds E, Smith C, Bowen JD, Guttmann CR, Nagy ZP, Simon J, Whitham R, Lovera J, Yadav V, Mass M et al: A highly immunogenic trivalent t cell receptor peptide vaccine for multiple sclerosis. Multiple sclerosis (2005) 11(5):552-561.

55. Braley-Mullen H, Tompson JG, Sharp GC, Kyriakos M: Suppression of experimental autoimmune thyroiditis in guinea pigs by pretreatment with thyroglobulin-coupled spleen cells. Cell Immunol (1980) 51(2):408-413.

56. Dua HS, Gregerson DS, Donoso LA: Inhibition of experimental autoimmune uveitis by retinal photoreceptor antigens coupled to spleen cells. Cell Immunol (1992) 139(2):292-305.

57. Fife BT, Guleria I, Gubbels Bupp M, Eagar TN, Tang Q, Bour-Jordan H, Yagita H, Azuma M, Sayegh MH, Bluestone JA: Insulin-induced remission in new-onset nod mice is maintained by the pd-1-pd-l1 pathway. $J$ Exp Med (2006) 203(12):27372747. 
58. Gregorian SK, Clark L, Heber-Katz E, Amento EP, Rostami A: Induction of peripheral tolerance with peptide-specific anergy in experimental autoimmune neuritis. Cell Immunol (1993) 150(2):298-310.

59. Karpus WJ, Pope JG, Peterson JD, Dal Canto MC, Miller SD: Inhibition of theiler's virus-mediated demyelination by peripheral immune tolerance induction. $J$ Immunol (1995) 155(2):947-957.

60. Kennedy KJ, Smith WS, Miller SD, Karpus WJ: Induction of antigen-specific tolerance for the treatment of ongoing, relapsing autoimmune encephalomyelitis: A comparison between oral and peripheral tolerance. J Immunol (1997) 159(2):1036-1044.

61. Kennedy MK, Tan LJ, Dal Canto MC, Tuohy VK, Lu ZJ, Trotter JL, Miller SD: Inhibition of murine relapsing experimental autoimmune encephalomyelitis by immune tolerance to proteolipid protein and its encephalitogenic peptides. $J$ Immunol (1990) 144(3):909-915.

62. Miller SD, Claman HN: The induction of hapten-specific t cell tolerance by using hapten-modified lymphoid cells. I. Characteristics of tolerance induction. $J$ Immunol (1976) 117(5 Pt 1):1519-1526.

63. Miller SD, Tan LJ, Kennedy MK, Dal Canto MC: Specific immunoregulation of the induction and effector stages of relapsing eae via neuroantigen-specific tolerance induction. Ann N Y Acad Sci (1991) 636(79-94. 
64. Miller SD, Wetzig RP, Claman HN: The induction of cell-mediated immunity and tolerance with protein antigens coupled to syngeneic lymphoid cells. $J \operatorname{Exp} M e d$ (1979) 149(3):758-773.

* Important study showing a novel tolerization strategy based on antigen-coupled cells.

65. Pope L, Paterson PY, Miller SD: Antigen-specific inhibition of the adoptive transfer of experimental autoimmune encephalomyelitis in lewis rats. $J$ Neuroimmunol (1992) 37(3):177-189.

66. Tan LJ, Kennedy MK, Dal Canto MC, Miller SD: Successful treatment of paralytic relapses in adoptive experimental autoimmune encephalomyelitis via neuroantigen-specific tolerance. J Immunol (1991) 147(6):1797-1802.

67. Turley DM, Miller SD: Peripheral tolerance induction using ethylenecarbodiimide-fixed apcs uses both direct and indirect mechanisms of antigen presentation for prevention of experimental autoimmune encephalomyelitis. $J$ Immunol (2007) 178(4):2212-2220.

68. Kohm AP, Turley DM, Miller SD: Targeting the tcr: T-cell receptor and peptidespecific tolerance-based strategies for restoring self-tolerance in cns autoimmune disease. International reviews of immunology (2005) 24(5-6):361-392.

69. Smarr CB, Hsu CL, Byrne AJ, Miller SD, Bryce PJ: Antigen-fixed leukocytes tolerize th2 responses in mouse models of allergy. $J$ Immunol 187(10):5090-5098.

70. Lutterotti A, Yousef S, Sputtek A, Stürner K, Stellmann J, Breiden P, Reinhardt S, Schulze C, Bester M, Heesen C, Schippling S et al: Antigen-specific tolerance by 
autologous myelin peptide-coupled cells - a phase i trial in multiple sclerosis. Science Translational Medicine (2013) in press

* First-in-man study using antigen -coupled cells as tolerogen for treatment of MS.

71. Getts DR, Turley DM, Smith CE, Harp CT, McCarthy D, Feeney EM, Getts MT, Martin AJ, Luo X, Terry RL, King NJ et al: Tolerance induced by apoptotic antigen-coupled leukocytes is induced by pd-11+ and il-10-producing splenic macrophages and maintained by $\mathbf{t}$ regulatory cells. $J$ Immunol 187(5):2405-2417.

72. Raiotach-Regue D, Grau-Lopez L, Naranjo-Gomez M, Ramo-Tello C, Pujol-Borrell R, Martinez-Caceres E, Borras FE: Stable antigen-specific t-cell hyporesponsiveness induced by tolerogenic dendritic cells from multiple sclerosis patients. Eur $J$ Immunol (2012) 42(3):771-782.

73. Lassmann H, Bruck W, Lucchinetti CF: The immunopathology of multiple sclerosis: An overview. Brain pathology (2007) 17(2):210-218.

74. Goebels N, Hofstetter H, Schmidt S, Brunner C, Wekerle H, Hohlfeld R: Repertoire dynamics of autoreactive $t$ cells in multiple sclerosis patients and healthy subjects: Epitope spreading versus clonal persistence. Brain (2000) 123 Pt 3(508518.

75. Tuohy VK, Yu M, Weinstock-Guttman B, Kinkel RP: Diversity and plasticity of self recognition during the development of multiple sclerosis. J Clin Invest (1997) 99(7):1682-1690.

** First study assessing longitudinally the developmental changes in diverstity and plasticity of myelin specific respones in MS patients. 
76. Tuohy VK, Yu M, Yin L, Kawczak JA, Kinkel PR: Regression and spreading of self-recognition during the development of autoimmune demyelinating disease. $J$ Autoimmun (1999) 13(1):11-20.

* Important study on epitope spreading in MS.

77. McRae BL, Vanderlugt CL, Dal Canto MC, Miller SD: Functional evidence for epitope spreading in the relapsing pathology of experimental autoimmune encephalomyelitis. $J$ Exp Med (1995) 182(1):75-85.

78. Vanderlugt CL, Miller SD: Epitope spreading in immune-mediated diseases: Implications for immunotherapy. Nat Rev Immunol (2002) 2(2):85-95.

* Important overview on epitope spreading in immune mediated disease.

79. Bielekova B, Sung MH, Kadom N, Simon R, McFarland H, Martin R: Expansion and functional relevance of high-avidity myelin-specific cd4 + t cells in multiple sclerosis. J Immunol (2004) 172(6):3893-3904.

80. Lennon VA, Wingerchuk DM, Kryzer TJ, Pittock SJ, Lucchinetti CF, Fujihara K, Nakashima I, Weinshenker BG: A serum autoantibody marker of neuromyelitis optica: Distinction from multiple sclerosis. Lancet (2004) 364(9451):2106-2112.

81. Hauser SL, Waubant E, Arnold DL, Vollmer T, Antel J, Fox RJ, Bar-Or A, Panzara M, Sarkar N, Agarwal S, Langer-Gould A et al: B-cell depletion with rituximab in relapsing-remitting multiple sclerosis. The New England journal of medicine (2008) 358(7):676-688.

82. Srivastava R, Aslam M, Kalluri SR, Schirmer L, Buck D, Tackenberg B, Rothhammer V, Chan A, Gold R, Berthele A, Bennett JL et al: Potassium channel kir4.1 as an 
immune target in multiple sclerosis. The New England journal of medicine (2012) 367(2):115-123.

83. McFarland HF, Frank JA, Albert PS, Smith ME, Martin R, Harris JO, Patronas N, Maloni $\mathrm{H}, \mathrm{McF}$ arlin $\mathrm{DE}$ : Using gadolinium-enhanced magnetic resonance imaging lesions to monitor disease activity in multiple sclerosis. Ann Neurol (1992) 32(6):758-766.

84. Miller DH, Barkhof F, Nauta JJ: Gadolinium enhancement increases the sensitivity of mri in detecting disease activity in multiple sclerosis. Brain (1993) 116 ( Pt 5)(1077-1094. 
Figure: Antigen specific approaches to induce immune tolerance in MS

The figure depicts the central structures targeted by current approaches to induce antigenspecific tolerance in MS.

Panel A: shows the trimolecular complex, consisting of the MHC, the specific peptide and the TCR. Interaction in these structures can lead to anergy, apoptosis of T cells or antiinflammatory cytokine secretion (bystander suppression). Induction of regulatory $\mathrm{T}$ cells is an additional mechanism for induction of tolerance.

Panel B: Induction of tolerance by antigen-coupled cells leads to apoptosis of coupled cells, which are phagocytosed by dendritic cells or macrophages and re-present the antigens in a tolerogenic way.

Table: Overview on recent and ongoing strategies to induce tolerance in MS. 


\section{Immune synapse}

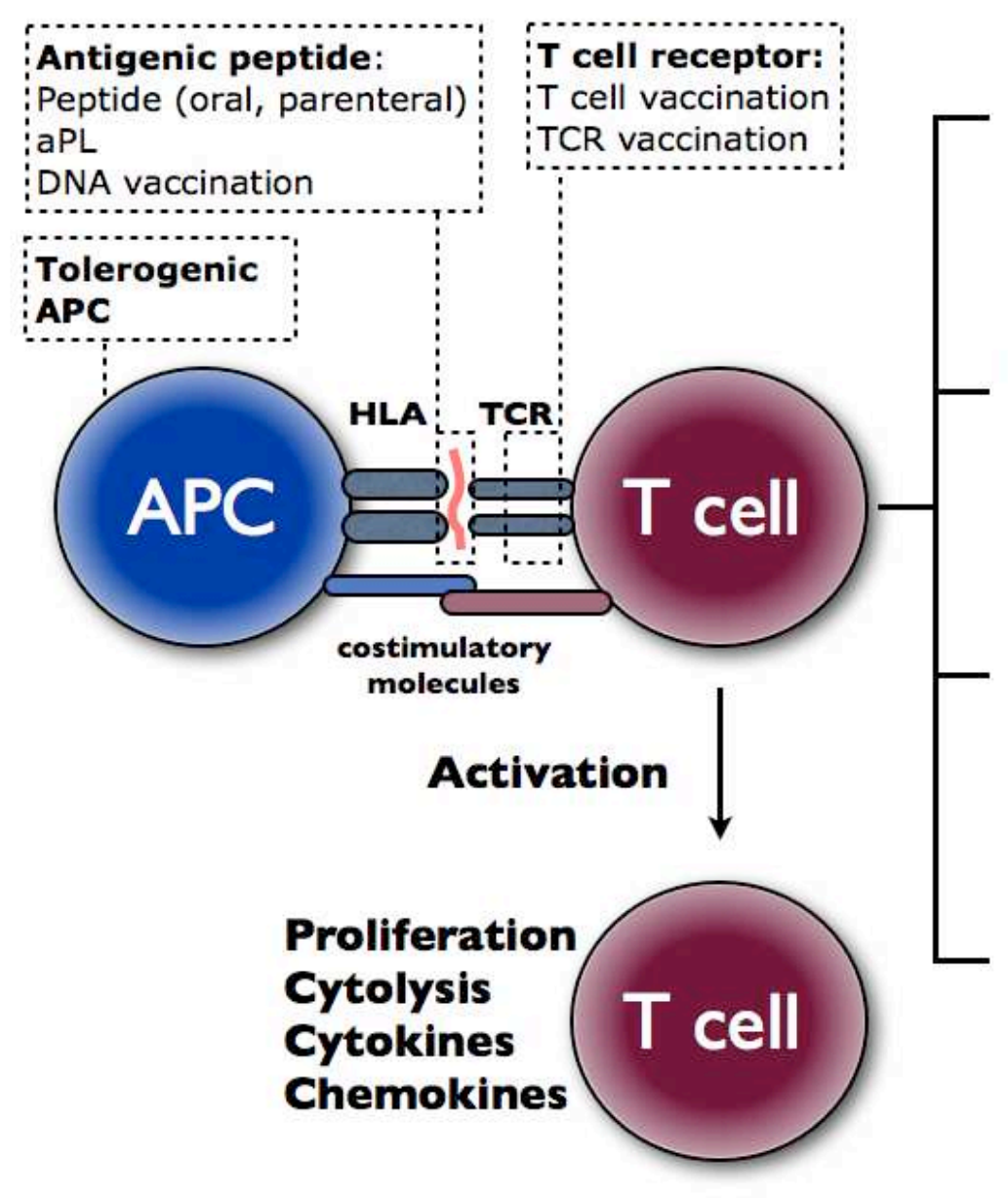

\section{Mechanisms of immune tolerance}

stimulation without costimulation

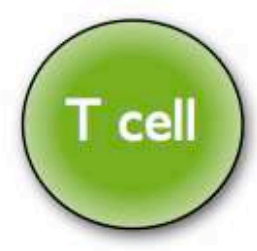

Anergy

interaction between

Fas and FasLigand

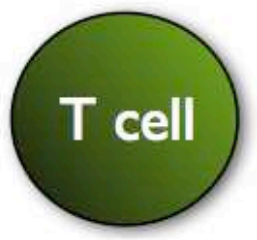

Apoptosis

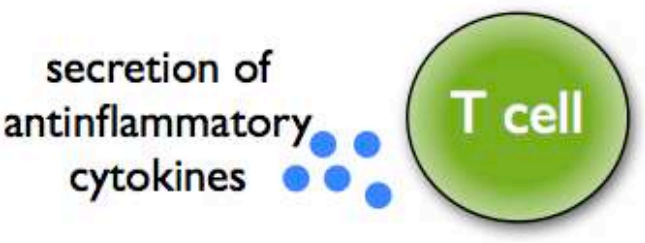

Bystander suppression

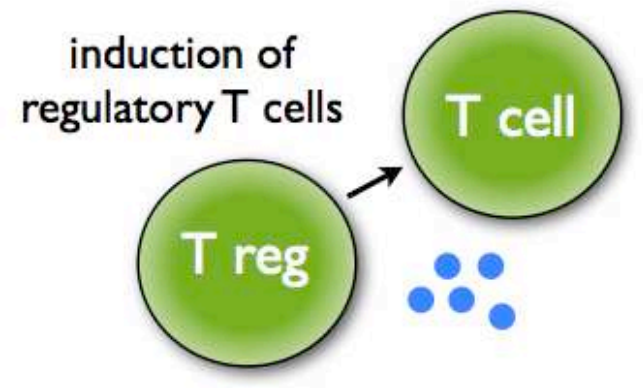

Regulatory T cells 


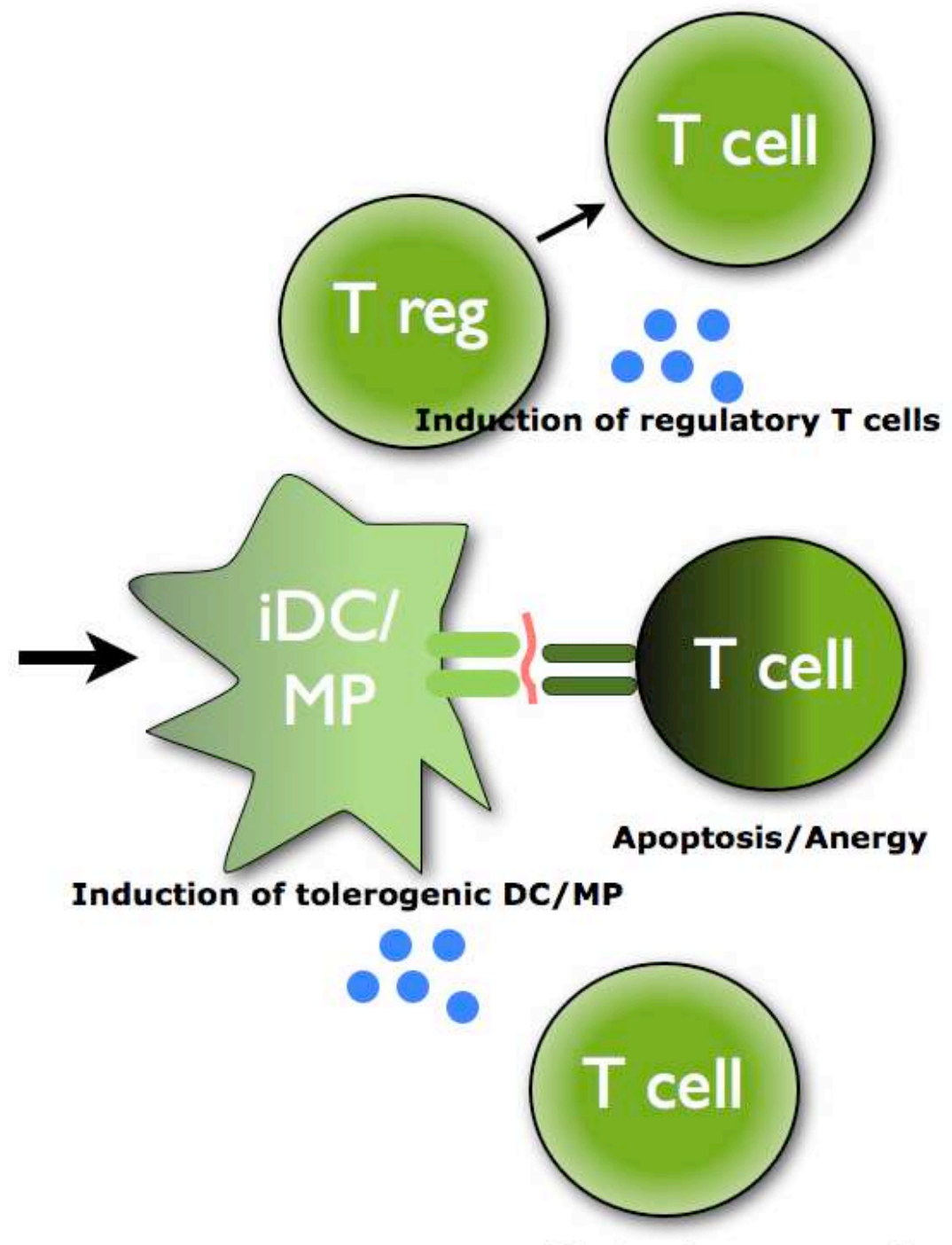

Indurtion of regulatory $\mathbf{T}$ cells

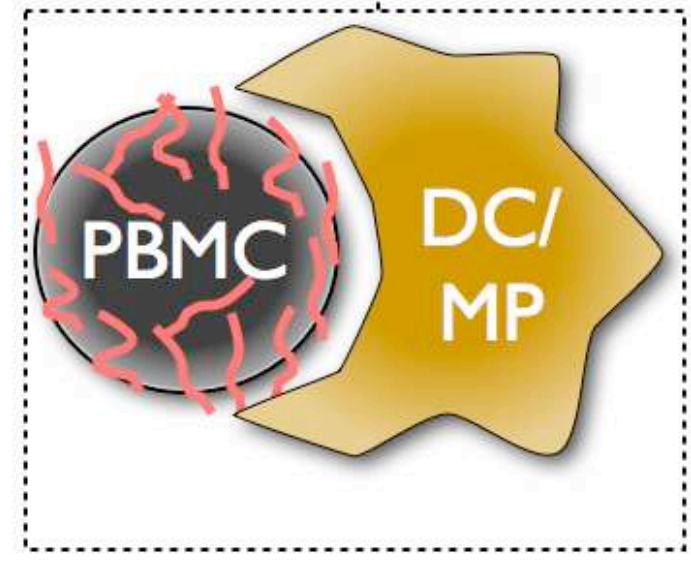

Bystander suppression 
Table: Overview on recent and ongoing strategies to induce tolerance in MS.

\begin{tabular}{|c|c|c|c|c|c|c|c|c|}
\hline $\begin{array}{l}\text { Antigen specific } \\
\text { therapy }\end{array}$ & Treatment & $\operatorname{RoA}^{1}$ & Tolerogen & $\begin{array}{c}\text { MS } \\
\text { course }\end{array}$ & $\mathbf{n}$ & Trial design & Result / Ref & Immune response \\
\hline $\begin{array}{l}\text { Transdermal myelin } \\
\text { peptides }\end{array}$ & $\begin{array}{l}\text { Synthetic myelin } \\
\text { peptides }\end{array}$ & t.d. & peptide & $\mathrm{RR}$ & 30 & $\mathrm{RCT}$ & $\begin{array}{l}\text { Safe, Reduced relapse } \\
\text { and MRI lesions / 30, } 31\end{array}$ & Induction of Tr1 cells \\
\hline Apitope & Synthetic peptides & sc. / id. & peptide & SP & 6 & Open label & not published / 29 & Induction of IL10 $\operatorname{Tr} 1$ cells \\
\hline $\begin{array}{l}\text { DNA vaccine } \\
\text { (BHT-3009) }\end{array}$ & $\begin{array}{l}\text { Plasmid encoding } \\
\text { full length human } \\
\text { MBP }\end{array}$ & i.m. & DNA & $\mathrm{RR}, \mathrm{SP}$ & 267 & Double blind, RCT & $\begin{array}{l}\text { Safe, well tolerated, } \\
\text { favourable on MRI / } 40\end{array}$ & $\begin{array}{l}\text { Downregulation of antigen } \\
\text { specific cellular and } \\
\text { humoral immune response }\end{array}$ \\
\hline MBP8298 & $\begin{array}{l}\text { Soluble peptide } \\
\text { (MBP82-98) }\end{array}$ & i.v. & peptide & SP & 612 & Double blind, RCT & $\begin{array}{l}\text { Benefit in HLA } \\
\text { DR2/DR4 patients / } 25\end{array}$ & \\
\hline $\begin{array}{l}\text { Soluble MHC loaded } \\
\text { with peptide }\end{array}$ & $\begin{array}{l}\text { Solubilized complex } \\
\text { of DR2 with MBP }\end{array}$ & & $\begin{array}{l}\text { peptide/MHC } \\
\text { complex }\end{array}$ & SP & 33 & $\begin{array}{l}\text { Double masked, } \\
\text { dose escalation }\end{array}$ & $\begin{array}{l}\text { Safe, no effect on clinical } \\
\text { activity / } \mathbf{2 6}\end{array}$ & No tolerization effect \\
\hline \multirow[t]{2}{*}{ APL - CGP77116 } & $\begin{array}{l}\text { Altered peptide } \\
\text { ligand }\end{array}$ & s.c. & peptide & $\mathrm{RR}$ & 8 & $\begin{array}{l}\text { Open label, MRI } \\
\text { controlled }\end{array}$ & $\begin{array}{l}\text { Stopped due to } \\
\text { exacerbations / } \mathbf{3 4}\end{array}$ & $\begin{array}{l}\text { Activation of MBP specific } \\
\mathrm{T} \text { cells / induction } \mathrm{Th} 2 \\
\text { response }\end{array}$ \\
\hline & $\begin{array}{l}\text { Altered peptide } \\
\text { ligand }\end{array}$ & s.c. & peptide & $\mathrm{RR}$ & 142 & Double blind, RCT & $\begin{array}{l}\text { Stopped due to } \\
\text { hypersensitivity / } \mathbf{3 5}\end{array}$ & Induction Th2 response \\
\hline TCR vaccination & $\begin{array}{l}\text { Trivalent TCR } \\
\text { peptide vaccine }\end{array}$ & & peptide & $\mathrm{RR}, \mathrm{SP}$ & 27 & Open label & $\begin{array}{l}\text { no progression in } \\
\text { disability / } \mathbf{5 5}\end{array}$ & $\begin{array}{l}\text { Induction of TCR specific } \\
\text { responses, Induction of } \\
\text { IL10 and FoxP3 T cells }\end{array}$ \\
\hline $\mathrm{T}$ cell vaccination & $\begin{array}{l}\text { Autologous myelin } \\
\text { reactive T cells }\end{array}$ & i.v. & cell & RR, CIS & 150 & $\mathrm{RCT}$ & $\begin{array}{l}\text { Safe, well tolerated, no } \\
\text { benefit on clinical and } \\
\text { MRI parameters / } \mathbf{5 0}\end{array}$ & \\
\hline
\end{tabular}




\begin{tabular}{|c|c|c|c|c|c|c|c|c|}
\hline & $\begin{array}{l}\text { Autologous myelin } \\
\text { reactive T cells }\end{array}$ & i.v. & cell & RP & 26 & $\begin{array}{l}\text { Double-blind, RCT } \\
\text { (sham-controlled) }\end{array}$ & $\begin{array}{l}\text { reduction in clinical } \\
\text { disease activity, no effect } \\
\text { on MRI / } \mathbf{5 2}\end{array}$ & $\begin{array}{l}\text { reduction in myelin reactive } \\
\mathrm{T} \text { cells }\end{array}$ \\
\hline & $\begin{array}{l}\text { Autologous myelin } \\
\text { reactive T cells }\end{array}$ & i.v. & cell & $\mathrm{RR}, \mathrm{SP}$ & 5 & open label & Safe, well tolerated / 47 & \\
\hline $\begin{array}{l}\mathrm{T} \text { cell receptor } \\
\text { ligands }\end{array}$ & $\begin{array}{l}\text { Recombinant HLA- } \\
\text { DR2/MOG35-55 } \\
\text { construct }\end{array}$ & i.v. & $\begin{array}{l}\text { peptide-HLA } \\
\text { construct }\end{array}$ & RR & 34 & $\begin{array}{l}\text { double blind, phase } \\
\text { I dose escalationl }\end{array}$ & $\begin{array}{l}\text { safe well tolerated, target } \\
\text { dose } 60 \mathrm{mg} / \mathbf{2 7}\end{array}$ & \\
\hline
\end{tabular}

1 RoA: Rout of administration; t.d.: transdermal; s.c.: subcutaneous; i.d.: intradermal; i.v.: intravenous; RR: relapsing-remitting; SP secondary progressive; RCT_ randomized controlled trial 